\title{
Idea Exchange Music Hub Hits the Right Note in Community
}

\author{
Greg Bester \\ Manager, Idea Exchange \\ Clemens Mill Library \\ gbester@ideaexhange.org
}

\begin{abstract}
The Cambridge Libraries and Galleries has made many changes over the last two years, rebranding as Idea Exchange and adding 3D printers, creative spaces and many on-site events. This article focuses on one of the organization's newest innovations, the addition of a Music Hub, and the challenges of creating a space where members can learn and collaborate musically without disturbing those around them.
\end{abstract}

\section{Keywords}

musical instruments; maker spaces; library as space

Over the last two years, The Cambridge Libraries and Galleries has been undergoing a transformation, one that welcomes innovation and change. Recently rebranded as Idea Exchange, the library's new name allows us to transform the way our members and community experience their local library and gallery space. Idea Exchange encompasses a new vision focused on a passion for art, reading, knowledge sharing, creating, and cultural programs. Gone is the library as a warehouse of books and other consumables. We believe the way forward is participation and cultural creation.

In June 2011, CEO Greg Hayton visited a number of cutting edge libraries in Europe and marveled at how they have embraced this new direction. There he noted the integration of cultural and social services with traditional book and information based services, the emphasis on music and art activities in library facilities, and the overall focus on programs and events taking place within the library walls. Returning with an invigorated enthusiasm, he began to evangelize staff in the new model. It wasn't long before the team at Idea Exchange became excited by the idea of moving beyond the traditional library model to one that empowers our members (formerly known as patrons) to become creators. 
One idea in particular resonated with Greg when travelling abroad: most libraries he visited in Scandinavia have adopted the public use of musical instruments in their spaces. This initiative fit perfectly into the Idea Exchange structure and was a natural fit for the Clemens Mill Location.

Clemens Mill is a shared facility with the local school board. It services a high school age population of about 1,600 as well as the local community. With demographics like these, the hope was that the addition of musical instruments would become a very popular addition to the collection.

Following the models witnessed in Finland and Denmark, questions arose: how to make this idea work in a public space? How will this allow musicians the opportunity to create and collaborate while keeping the noise level low enough to minimize the invasion of "quiet" space for other members? How would members react?

After doing extensive research, including discussions with a local supplier of musical instruments, the team came across a small mixing unit called a "Jam Hub." This genius device allows up to six instruments to be plugged in at one time, and musicians have the choice of hearing their own instrument or mixing the other instruments into their headphones. It also has the capability of adding speakers for public performances, should the occasion arise. With the noise problem seemingly overcome, new equipment was acquired: two electric guitars, a keyboard and a set of electric drums. Though we were originally leery of drums, it was remarkable how relatively quiet modern electric drums can be. The use of rubber cymbals and mesh material drum heads dampened the sound an amazing amount. The team was inspired by the new additions, beaming with confidence at the discreet nature of the instruments.

The Music Hub was presented in early 2014 to an enthusiastic response, both from the students and the general public. Using the library's existing software and sign-out records for members to reserve their sessions, schedules were created for members to reserve playing time.

With the aid of a local music school, a custom program was created to introduce instrumental music to teens. The response was staggering; the program was full almost immediately, with requests to run more sessions coming in daily.

Along with the extremely positive reaction to this initiative, people who wouldn't generally come to the location now had a reason to visit and use the space. This includes one wonderful young man, who, upon seeing the drum set, declared it a "Godsend" and quickly became a regular presence at Clemens Mill.

On his first visit, the library's confidence in the quiet nature of these precious instruments was shaken. When he began to play, it was clear we had underestimated the level of noise a genuine drummer could generate. The kick 
bass drum was the main issue. Even though the sound was electronic, there was still a clapper meeting a target on the drum set, making enough sound to disturb other members. It was now apparent, if the drums were to remain a permanent piece in this collection, a solution needed to be found to minimize the sound and please the non-musical members.

The team went back to the internet to research noise barriers, many of which were deemed esthetically unappealing and not convincing as a concrete answer to this issue. Eventually, one struck a chord: a small German company, based in Serbia, had introduced an inexpensive electronic device that would fit the drum set and eliminate the need for a physical striker. Bingo. This discovery has been hugely helpful in reducing the sound created by the drum set.

The Idea Exchange Music Hub is an innovative initiative that presents youth and adults in the community with the opportunity to discover a passion for music, something many members may not have otherwise had the privilege to experience. As any new venture, it has not been without challenges but overall has been an outstanding success. Connecting with members and encouraging growth within the community are important principles held within the walls of Idea Exchange. The addition of the Clemens Mill Music Hub is a step in the right direction in offering the public a space to innovate, create and grow.

For more information on the Idea Exchange | Clemens Mill Music Hub please visit: http://www.cambridgelibraries.ca/teens/ideas/music-hub 